\title{
DAMPAK TEORI DOMINO DI NEGARA-NEGARA AFRIKA UTARA
}

\author{
Terry Irenewati dan Aman \\ FIS, Universitas Negeri Yogyakarta \\ email: terryirenewaty@rocketmail.com
}

\begin{abstract}
Abstrak: Dampak Teori Domino di Negara-Negara Afrika Utara. Penelitian ini bertujuan untuk mengungkap keterkaitan revolusi di negara-negara Afrika Utara, terutama yang terjadi di Mesir dan Libya yang notabene mayoritas penduduknya memeluk agama Islam. Penelitian ini menggunakan metode historis kritis, kritis meliputi 5 tahap, yaitu: (1) pemilihan topik, (2) heuristik, (3) verifikasi (keabsahan sumber, kritik sejarah), (4) interpretasi: analisis dan sintetis, dan (5) historiografi. Hasil dari penelitian ini menunjukkan bahwa terdapat kemiripan penyebab revolusi yang terjadi di negara-negara Afrika Utara, meliputi Mesir dan Libya. Kemiripan tersebut terletak pada dinamika pemerintahan yang sama-sama dipimpin oleh pemimpin yang telah lama berkuasa, sistem diktator, dan rendahnya tingkat kesejahteraan sosial, serta minimnya demokrasi. Hal ini sejalan dengan teori domino yang menjelaskan bahwa peristiwa yang terjadi di suatu negara bisa berdampak pada negara sekitar yang memiliki karakteristik yang sama.
\end{abstract}

Kata kunci: Teori domino, revolusi Mesir, revolusi Libya

\begin{abstract}
The Influences of Domino Theory in North African Countries. This research aims to explore the relation of revoution in north African countries especially Egypt and Libya of which most citizens are moslem. This research employs a critical historic method, includes 5 stages, namely: (1) topic selection, (2) heuristic, (3) verification (source validity, critical historic), (4) interpretation: analysis and synthesis, and (5) historiography. The research findings show that there are some similarities on the causes of revolution happening in north African countries including Egypt and Lybia. The similarities lie on the leaders who govern the nation i.e. both countries are governed by the leader who has led in a long term; dictator system; low social welfare; and less democratic. This is in line with the theory of domino which states that the crisis which occurs in a certain country may influence nearby countries having similar characteristics.
\end{abstract}

Keywords: Domino theory, Egypt revolution, Libya revolution

\section{PENDAHULUAN}

Kebangkitan negara Islam merupakan hal yang sangat penting bagi kaum muslim. Kebangkitan Islam akan selalu berhubungan dengan politik di negara yang bersangkutan. Politik di negara Islam membahas ide-ide tentang komunitas muslim yang dipimpin oleh seorang khalifah/pemimpin yang memiliki status sebagai pemimpin politik dan agama yang harus ditaati oleh seluruh anggota komunitas muslim (Hanafi dan
Al Jabiri, 2003:58). Ketika pemerintah tidak sesuai dengan harapan rakyat, maka rakyat melakukan gerakan untuk menjatuhkannya. Di Afrika Utara, gerakan menjatuhkan penguasa dilakukan melalui jalan revolusi.

Gerakan revolusi pertama kali terjadi di Tunisia guna menjatuhkan rezim diktator Zein Al Abidin Ben Ali. Ben Ali menjadi presiden di Tunisia sejak November 1987 melalui kudeta damai 7 November 1987, presiden terdahulunya 
Bourguiba (Tamburaka, 2011:19). Tunisia di bawah Ben Ali menerapkan kebijakan ekonomi liberal, dengan memperjuangkan reformasi ekonomi dan investasi asing. Tunisia termasuk negara dengan tingkat pengangguran tinggi, terutama di kalangan pemuda dan banyak pengusaha kecil yang tidakmampubersaingdenganasing. Konsisi perekonomian yang memprihatinkan memicu terjadinya kerusuhan dan sikap rakyat yang radikal, seperti yang dilakukan Muhammad Bouazizi (26 tahun). Ia adalah seorang pedagang sayur di kota Sidi Bouzid. Ketika ia sedang merapikan dagangannya, ia didatangi aparat keamanan karena tidak memiliki izin berdagang. Gerobaknya harus disita, ia harus menanggung denda, dan dipukuli. Tidak terima dengan tindakan itu, ia melaporkan kejadian tersebut ke kantor Gubernur Sidi Bouzid, namun tidak ditanggapi. Ia kemudian melakukan aksi bakar diri di depan kantor tersebut. Dia dilarikan ke rumah sakit kota Ben Arous dan menjalani rawat inap. Muhammad Bouazizi meninggal pada tanggal 4 Januari 2011, 17 hari setelah melakukan aksi bakar diri.

Rezim pemerintahan otoriter dan dianggap tidak demokratis, mengekang ke-bebasan berpendapat memicu rakyat Tunisia untuk menjatuhkan rezim pemerintahan Ben Ali. Demonstrasi rakyat Tunisia terjadi pada bulan Desember sampai Januari 2011. Revolusi yang terjadi di Tunisia kemudian memicu terjadinya revolusi negara Arab lainnya, seperti Mesir dan Libya. Revolusi Mesir menjatuhkan rezim diktator Hosni Mubarak yang berkuasa sejak tahun 1981. Revolusi ini dipicu oleh beberapa faktor, yaitu sistem sosial dan ekonomi yang tidak merata, pengekangan pemerintah terhadap rakyat Mesir terutama dalam bidang politik, aktivitas keagamaan yang dikooptasi kepentingan penguasa, dan kebijakan Mesir yang cenderung pro Amerika Serikat, Barat, dan Israel (Ricardo, 2011: 44-45).
Terjadinya revolusi Mesir berawal dari meninggalnya seorang pemuda bernama Khaled Said (28 tahun) pada bulan Juni tahun 2010. Khaled Said meninggal karena disiksa oleh sejumlah aparat kepolisian yang di sebuah warung internet di kota Alexandria. Foto Khaled Said dalam kondisi mengenaskan segera tersebar di internet. Hal ini menarik simpati seorang pemuda bernama Wael Ghonim untuk membuat laman facebook bernama May Name Is Khaled Said. Alamat facebook ini kemudian diberangus oleh pemerintah. Ia kemudian membuat laman baru dengan nama We are All Khaled Said (Tamburaka, 2011:75). Facebook ini digunakan untuk mengkoordinasi rakyat guna melakukan demonstrasi terhadap pemerintah yang berkuasa. Tokoh pergerakan online selain Wael Ghonim adalah Asmaa Mahfouz (26 tahun). Ia mengunggah orasi-orasi dan video-video lewat jejaring sosial. Pada tanggal 18 Januari 2011 menceritakan empat warga Mesir yang membakar diri sebagai bentuk protes terhadap kemiskinan, kelaparan, dan keterpurukan nasib. Keempat warga yang membakar diri terpicu dari revolusi Tunisia. Akhirnya demonstrasi terjadi di kota-kota seperti Alexandria, Suez, Kairo, dan kota lainnya. Demonstrasi rakyat berpusat di Alun-alun Tahrir Kairo. Demonstrasi ini akhirnya berhasil menjatuhkan rezim Hosni Mubarak pada 11 Februari 2011.

Gerakan revolusi kemudian menjalar ke Libya guna menjatuhkan rezim Muammar Qadhafi. Muammar Qadhafi menjabat presiden Libya pada tahun 1969, setelah menjatuhkan Raja Said melalui kudeta putih. Awal kekuasaannya Muammar Qadhafi mulai menggulirkan kebijakan anti-Barat. Kebijakan pemerintahnya lebih difokuskan pada bidang militer daripada ekonomi. Muammar Qadhafi menggunakan militer untuk membunuh lawan politiknya. Gerakan revolusi di Tunisia dan Mesir memicu rakyat Libya untuk menjatuhan rezim yang berkuasa. Demonstrasi 
dilakukan pada 17 Februari 2011 di seluruh penjuru kota, namun Muammar Qadhafi tetap tidak bergeming. Demonstrasi rakyat Libya mendapat bantuan dari Barat, rakyat kemudian melakukan demonstrasi ke Tripoli pada 23 Agustus 2011. Pertempuran ini dikenal dengan nama Battle of Tripoli (Pertempuran Tripoli). Setelah beberapa bulan pertempuran Tripoli, Muammar Qadhafi dinyatakan Tewas pada 20 Oktober 2011 (Bahaudin, 2012:201).

Penelitian ini bertujuan untuk mengungkap keterkaitan revolusi di negara-negara Afrika Utara, yaitu Tunisia, Mesir, dan Libya yang notabene mayoritas penduduknya memeluk agama Islam. Namun, pembahasan mengenai Tunisia hanya sebagai pengantar. Selebihnya peneliti fokus pada revolusi yang terjadi di Mesir dan Libya. Faktor kemiripan penyebab terjadinya revolusi dan dinamika pemerintahan di kedua negara tersebut menjadi bagian yang dikaji dalam penelitian ini. Konflik yang terjadi di Tunisia, Mesir, dan Libya merupakan suatu efek domino yang terjadi karena ketiga negara tersebut bertetangga.

Efek domino merupakan suatu istilah yang sudah lama diperkenalkan oleh para ahli strategi internasional untuk menggambarkan hubungan antara suatu ideologi dan pengaruhnya, suatu agama, budaya, kebijakan politik dan moneter maupun hubungan antara suatu negarabangsa dengan mengambil suatu fenomena susun-bangun kartu domino, dan apabila salah satu kartu itu jatuh baik secara sengaja atau lemah secara alamiah, maka seluruh rangkaian kartu domino tersebut akan jatuh secara berurutan. Adapun secara lebih jelas mengenai revolusi yang terjadi di Mesir dan Libya akan dijelaskan pada bagian hasil dan pembahasan.

\section{METODE}

Metodologi atau science of methods adalah ilmu yang membicarakan jalan, dalam metodologi diuraikan berbagai jenis penulisan sejarah. Tata cara dalam penulisan penelitian sejarah memiliki perbedaan dengan ilmu-ilmu lainnya. Penelitian ini menggunakan metode sejarah kritis (historis kritis) menurut Kuntowijoyo yang meliputi lima tahap penulisan, yaitu: (1) pemilihan topik, (2) heuristik, (3) verifikasi (keabsahan sumber, kritik sejarah), (4) interpretasi: analisis dan sintetis, dan (5) historiografi (2003:91).

Pemilihan topik merupakan langkah awal dalam melakukan penulisan penelitian sejarah. Topik penulisan diambil berdasarkan ketertarikan dan intelektualitas penulis terhadap tema yang akan dikaji. Diharapkan hal ini dapat mempermudah penulis dalam mengkaji tema tentang "Teori Domino dalam Revolusi Negara-Negara di Afrika Utara".

Heuristik atau heurisken berasal dari bahasa Yunani yang berarti menemukan. Heuristik berarti kegiatan mencari sumber-sumber sejarah, baik berupa sumber benda, sumber tertulis maupun sumber lisan. Sumber sejarah adalah segala sesuatu yang secara langsung atau tidak langsung menceritakan tentang sesuatu kenyataan atau kegiatan manusia pada masa lalu (Sjamsuddin, 2012:7475). Pada penelitian ini, penulis mencari sumber-sumber tentang Revolusi negaranegara di Afrika Utara.

Penulisan penelitian ini menggunakan sumber sejarah primer dan sekunder. Sumber primer memuat bahan-bahan asli, sedangkan sumber sekunder memuat sumber-sumber yang telah digarap. Kesaksian langsung seorang pelaku sejarah atau saksi sejarah menggunakan mata kepala sendiri atau menggunakan alat mekanis termasuk dalam sumber primer (Gottschalk, 1982:85). Sumber primer dalam penulisan ini adalah artikel dari surat kabar terbitan nasional yang memuat tulisan mengenai revolusi negaranegara di Afrika Utara dan pemberitaan media negara-negara di Afrika Utara yang 
mengalami revolusi. Surat kabar yang digunakan sebagai sumber oleh penulis dapat dilihat pada daftar pustaka.

Sumber sekunder merupakan sumber yang tidak berasal pada saat peristiwa terjadi (Hamid dan Madjid, 2011:44). Sumber sekunder tidak berasal dari kesaksian pandangan langsung atau pandangan pertama melainkan berasal dari kesaksian orang yang tidak hadir dalam peristiwa.

Verifikasi yaitu memilih dan menguji sumber-sumber sehingga benar-benar me-rupakan sumber sejarah yang valid dan dapat dipertanggungjawabkan. Kegiatan ini bertujuan untuk memperoleh data yang memiliki validitas dan reliabilitas, sehingga semua data sesuai dengan fakta-fakta sejarah yang sesungguhnya (Daliman, 2012:66). Adapun langkahlangkah verifikasi meliputi: Autentisitas/ kritik ekstern. Kegiatan ini bertujuan memastikan kesejatian atau ketulenan antara bahan-bahan (Sidi Gazalba, 1981: 115). Misalnya pada dokumen tertulis perlu dilakukan penelitian terhadap kertas, tinta, gaya bahasa maupun ungkapan. Kredibilitas/kritik intern. Setelah menentukan bahwa sumber yang digunakan otentik. Selanjutnya akan meneliti apakah dokumen yang digunakan dapat dipercaya. Setelah semua dokumen diteliti akan mendapatkan sumber yang kredibel atau dapat dipercaya kebenarannya.

Penulisan penelitian tentang "Dampak Teori Domino di Negara-Negara Afrika Utara" ini menggunakan surat kabar sebagai sumber primer dan telah dilakukan penyeleksian terhadap surat kabar tersebut agar kredibel dengan judul penelitian.

Interpretasi atau disebut penafsiran adalah proses menafsirkan fakta sejarah yang telah ada. Subjektivitas merupakan hal yang perlu dihindari dalam interpretasi meskipun kadang perlu dilakukan. Interpretasi mempunyai dua bagian, yaitu: 1) Analisis, berarti menguraikan. Analisis bertujuan untuk mendapatkan faktafakta dalam penelitian. 2) Sintesis. Setelah dilakukan analisis dan mendapatkan fakta, langkah selanjutnya adalah melakukan penyatuan terhadap fakta-fakta yang berupa data. Dengan dilakukannya analisis dan sintetis maka akan memperoleh kesimpulan dan maknanya.

Historiografi atau penulisan sejarah adalah gambaran masa lampau yang tersusun secara sistematis, bulat dan jelas dalam bentuk cerita sejarah. Aspek kronologis sangat penting dalam penulisan sejarah karena dapat mengetahui perubahan dan perkembangan dalam suatu peristiwa sejarah secara urut sehingga mudah untuk dipahami. Historiografi merupakan tahap terakhir, penulis menyajikan semua fakta dalam bentuk tulisan dari hasil penelitian mengenai "Dampak Teori Domino di Negara-Negara Afrika Utara”.

\section{HASIL DAN PEMBAHASAN \\ Revolusi Mesir \\ Jalannya Revolusi Menjatuhkan Hosni Mubarak}

Gerakan revolusi dimulai pada tanggal 25 Januari 2011. Jutaan rakyat Mesir meliputi semua kalangan, baik kaum moderat maupun ekstremis, Muslim maupun Kristen, laki-laki maupun perempuan, tua maupun muda, konservatif maupun liberal, semua kalangan masyarakat Mesir turun ke jalan guna menuntut keadilan.

Demi mengamankan situasi Mesir, pemerintah menggerakkan polisi antihuru hara yang dipersenjatai tongkat, gas air mata, dan meriam air ke lapangan. Pada tanggal 27 Januari 2011, Mohammad El Baradei kembali ke Mesir dari Wina dan menyatakan ia siap untuk mempimpin gerakan demonstrasi (Tamburaka, 2011:77-79). Oposisi lain yang cukup kuat adalah Ikhwanul Mulimin sebagai organisasi terlarang. Gerakan demonstrasi masyarakat Mesir kemudian menyeluruh 
meliputi sebagian besar masyarakat kotakota di Mesir yang membuat masyarakat semakin anti-pemerintah.

Pada 29 Januari 2011, Hosni Mubarak menyatakan akan merombak kabinet tanpa menyatakan mundur dari jabatannya. Hal ini membuat rakyat Mesir semakin marah, demonstrasi terus berlanjut menuntut turunnya Hosni Mubarak dari jabatan presiden. Pada waktu itu juga, Hosni Mubarak menunjuk seorang wakil presiden, Omar Sulaiman setelah beberapa kali menjadi pemimpin tunggal Mesir tanpa didampingi wakil presiden. Sejak awal demonstrasi hingga tanggal 1 Februari Hosni Mubarak menyatakan dirinya tak akan mundur dari jabatannya, ia akan mundur pada bulan September mendatang ketika masa jabatan habis (Ricardo, 2011:11-12). Gerakan demonstrasi rakyat Mesir terjadi di kota-kota di Mesir, seperti Kairo, Alexandria, Suez, dan lain-lain. Demonstrasi rakyat terbesar berpusat di Alun-alun Tahrir, Kairo. Protes massa ini menimbulkan bentrok dengan aparat kepolisian, kemudian pada siang hari di 28 Januari 2011 pemerintah menggunakan militer untuk mengambil alih keamanan demonstran (Tamburaka, 2011:77-79).

Pada hari Jum'at 11 Februari 2011 Hosni Mubarak mengundurkan diri sebagai presiden dan kontrol atas negara Mesir diserahkan kepada Dewan Agung Militer, yang diketuai oleh Menteri Pertahanan Husein Tantawi. Naiknya Dewan Agung Militer menjadi pemerintah transisi Mesir ini setelah gelombang demonstrasi rakyat Mesir berlangsung selama 18 hari, yang terhitung sejak 25 Januari lalu. Pasca demonstrasi menjatuhkan Hosni Mubarak, demonstrasi terus berlanjut dengan mendesak pemerintah transisi untuk menunjuk Dewan Presiden, membubarkan parlemen, dan membebaskan tahanan politik.

Korban yang telah gugur dalam revolusi sebanyak 846 jiwa beserta ribuan yang terluka. Sedangkan sasaran pelaku pembunuhan itu ditujukan kepada mantan presiden Hosni Mubarak, Menteri Dalam Negeri Al Adly, dan perwira polisi. Mantan Menteri Dalam Negeri Habib AlAdly telah divonis 15 tahun penjara karena melakukan tindak korupsi, ia juga akan kembali diadili terkait tindak pembunuhan secara sengaja terhadap para pengunjuk rasa dalam revolusi lalu (Kompas, Rabu 6 Juli 2011).

Rakyat Mesir tidak sepenuhnya menuntut Hosni Mubarak turun dari jabatannya. Ribuan orang menggelar aksi demonstrasi di Alun-alun Tahrir menuntut Hosni Mubarak turun, sedangkan rakyat pendukung Hosni Mubarak melakukan demonstrasi di depan gedung stasiun televisi pemerintah. Mereka melakukan aksi ini setelah presiden dalam pidatonya menegaskan dirinya tidak akan mundur sebelum masa jabatannya berakhir pada bulan September mendatang. Mereka kemudian bergerak menuju Alun-alun Tahrir tempat demonstran anti-pemerintah berkumpul. Akhirnya bentrokan percah antara rakyat pendukung Hosni Mubarak dengan rakyat anti-Hosni Mubarak (Ricardo, 2011:7172). Hal ini mengakibatkan ke-kacauan di Mesir bertambah, bukan hanya rakyat dengan pemerintah, ditambah sesama rakyat Mesir.

Usaha yang dilakukan rakyat ini akhirnya sedikit terbayarkan. Pada tanggal 11 Februari 2011, di hari ke-18 demonstrasi rakyat Mesir, Hosni Mubarak menyatakan mundur dari jabatannya. Pengumuman ini disampaikan oleh wakil presiden Omar Sulaiman melalui stasiun televisi pemerintah. Selanjutnya pemerintahan Mesir akan diambil alih Dewan Agung Militer sebagai pemerintah transisi.

\section{Akhir Jatuhnya Pemerintahan Hosni Mubarak}

Pada tanggal 12 April 2011, Kejaksaan Mesir, Kairo memutuskan untuk menahan 
mantan Presiden Hosni Mubarak dan kedua putranya, Alaa Mubarak dan Gamal Mubarak guna keperluan penyidikan. Ketika ia diperiksa oleh tim kejaksaan di Al Tor, ibu kota propinsi Sinai Selatan mendadak tekanan darahnya tidak normal dan mengalami gangguan jantung sehingga ia segera dilarikan ke rumah sakit di Sharm El Seikh, Sinai Selatan. Setelah kesehatan mantan presiden membaik tim kejaksaan melanjutkan penyidikan di kamar 304 rumah sakit itu. Hari berikutnya, kedua putra Mubarak dipindahkan ke penjara Tora di Kairo (Kompas, Kamis 14 April 2011).

Mantan presiden Hosni Mubarak ditahan dengan tuduhanlima perkara, yaitu terlibat dalam pembunuhan pengunjuk rasa di Alun-alun Tahrir, memiliki rekening rahasia terkait perpustakaan Alexandria, menggelapkan uang negara, memperkaya diri secara tidak sah, dan memberikan fasilitas kepada pengusaha yang juga teman dekatnya, yaitu Hussein Salem.

Pada tanggal 25 Juli 2011 pengadilan Kairo melakukan sidang awal terkait kasus Hosni Mubarak dan mantan Menteri Dalam Negeri Habib Al-Adly serta enam pembantu lainnya. Situasi di persidangan ricuh, sehingga sidang akan dimulai pada tanggal 3 Agustus 2011. Keputusan ini disampaikan oleh Hakim Ketua Abdel Salam Gomaa (Kompas, Selasa 26 Juli 2011).

Sidang mantan presiden Hosni Mubarak dikawal oleh 8.200 aparat, yang terdiri dari polisi dan tentara. Menteri Dalam Negeri Mesir, Mansour El Essawi mengatakan bahwa pengamanan akan dilakukan melalui tiga tahap. Pengamanan dilakukan mulai dari penerbangan dari rumah sakit Sharm El Sheikh menggunakan pesawat militer ke pengadilan di Akademi Kepolisian di Kairo, dilanjutkan pengamanan ketika sidang berlangsung, dan pengamanan saat kembali ke Sharm El Sheikh. Hosni Mubarak sendiri masuk ke ruang sidang dalam posisi berbaring di atas tempat tidur rumah sakit (Kompas, Rabu 3 Agustus 2011).

Pada Sabtu, 2 Juni 2012, Hakim Ketua Ahmed Rafaat memutuskan mantan presiden Mesir Hosni Mubarak diberi hukuman penjara seumur hidup dan mantan Menteri Dalam Negeri Habib Al Adly dengan hukuman serupa. Kedua putra Hosni Mubarak Gamal Mubarak dan Alaa Mubarak beserta beberapa aparat kepolisian yang dituduh terlibat dalam aksi pembunuhan para demonstran dibebaskan, meskipun diberhentikan dari jabatannya (Kompas, Minggu 5 Juni 2012).

Partai Demokrasi Nasional (National Democratic Party/NDP) berpusat di dekat Alun-alun Tahrir, Kairo dan beberapa kantor di daerah dibakar massa pada tanggal 28 Januari 2011 (Kompas, Senin 18 April 2011, hlm. 10). Partai Demokrasi Nasional berkuasa di Mesir sejak masa pemerintahan presiden Anwar Sadat hingga presiden Hosni Mubarak. Pemerintah yang berkuasa di Mesir berada di bawah naungan Partai Demokrasi Nasional. Jatuhnya rezim Hosni Mubarak di Mesir pada 11 Februari 2011 membuka lembaran baru bagi Mesir. Setelah melalui perjalanan panjang sejak demonstrasi hingga diadakan pemilihan umum presiden dan parlemen baru, Mesir sekarang dipimpin oleh Muhammad Mursi, yang notabene berasal dari partai oposisi Partai Demokrasi Nasional, Ikhwanul Muslimin.

\section{Revolusi Libya}

Seperti di Tunisia dan Mesir. Gelombang protes di kedua negara tersebut berhasil menjatuhkan rezim diktator yang lama dan memberikan kemenangan bagi rakyat Mesir dan Tunisia. Masyarakat Libya yang melihat fenomena tersebut tidak tinggal diam. Masyarakat Libya kemudian menggunakan momentum tersebut untuk menjatuhkan rezim diktator yang telah lama berkuasa di negara mereka. 
Berbagai aksi demonstrasi yang dilakukan oleh para pemuda dan masyarakat yang menginginkan perubahan pun terjadi. Perang sipil yang terjadi di Libya atau yang dikenal dengan Gerakan Revolusi Libya merupakan perang yang terjadi di Libya antara tentara yang pro terhadap rezim Khadafi melawan masyarakat Libya yang anti terhadap rezim Khadafi. Kemelut antara masyarakat pro dan kontra di Libya dimulai dengan adanya protes damai pada tanggal 15 Februari 2011 yang kemudian mendapat perlawanan oleh militer Libya. Akhirnya gerakan protes tersebut meningkat dan terjadi di seluruh negeri. Hal tersebut kemudian berubah menjadi sebuah gerakan pemberontakan bersenjata untuk menurunkan rezim Khadafi.

Konflik yang diawali oleh gerakan demonstrasi masyarakat Libya terjadi karena selama masa Pemerintahan Khadafi masyarakat Libya merasa tidak mendapatkan kesejahteraan dalam hal kebebasan untuk berbicara dan menyatakan pendapat. Khadafi yang menjadi pemimpin Libya mengenai perjuangannya dalam Revolusi Al-Fatah pada tahun 1969 itu pada mulanya muncul sebagai pemimpin Libya yang bertujuan mempersatukan seluruh negara Arab dan menentang dominasi Amerika di tanah arab, serta mengusir kaum zionis dari muka bumi sejalan dengan apa yang dicitacitakan oleh Gamal Abdul Nasser (Agung, 2011:17). Pada awal pemerintahannya, Khadafi menghapus seluruh sistem konstitusi Libya yang digunakan pada masa pemerintahan Raja Idris pada tahun 1951, kemudian memperkenalkan falsafah politiknya ke dalam konstitusi di Libya.

Khadafi merupakan seorang pemimpin Libya yang telah berkuasa selama 42 tahun melalui sebuah kudeta terhadap pemimpin Libya sebelumnya, yaitu Raja Idris pada tahun 1969. Kedua belah pihak yaitu oposisi dan pihak pemerintahan Khadafi saling berebut kekuasaan atas Libya. Khadafi bertujuan untuk mempertahankan kekuasaannya atas Libya dan pihak oposisi yang terdiri dari rakyat Libya yang merupakan pihak yang tidak puas terhadap sistem pemerintahan menginginkan adanya perubahan dan pembaharuan struktur politik dan pemerintahan di Libya ke arah yang lebih baik dan demokratis.

Pada tanggal 15 Februari 2011, suatu gerakan protes dilakukan oleh para demonstran di Libya. Gerakan ini kemudian mendapat perlawanan oleh rezim Khadafi. Pemerintah Khadafi menganggap para demonstran sebagai penghianat yang menentang pemerintahannya. Dalam upayanya meredam aksi yang dilakukan para demonstran, Khadafi kemudian menggunakan kekuatan militer Libya yang terdiri dari angkatan darat, laut, dan udara. Serangan ini ditujukan bagi para pemberontakyangterus melakukan aksinya di berbagai wilayah di Libya. Hal tersebut berdampak pada banyaknya warga sipil yang menjadi korban selama pergolakan berlangsung. Situasi memanas tersebut berubah menjadi konflik bersenjata yang pada akhirnya memaksa Khadafi mundur dari jabatannya sebagai orang nomor satu di Libya tersebut.

Revolusi Libya memberikan dampak yang sangat besar bagi Libya maupun negara-negara lain. Dampak yang paling besar akibat revolusi Libya adalah banyaknya korban jiwa yang berjatuhan. Selain itu ketidak-stabilan politik yang terjadi menjelang revolusi dan setelah revolusi membuat kehidupan berbangsa dan bernegara Libya semrawut. Para pelajar asing dan pekerja asingyang berada di Libya memilih untuk mengevakuasi diri mereka keluar dari Libya demi keamanan. Revolusi Libya juga mengakibatkan ketidak-stabilan harga minyak dunia, dimana harga minyak dunia melonjak hingga 100 dolar per barel (Tamburaka, 2011:221). 


\section{SIMPULAN}

Revolusi yang terjadi di tiga negara meliputi Tunisia, Mesir, dan Libya memiliki beberapa persamaan dan perbedaan. Letak persamaannya adalah ketiga negara tersebut sama-sama dipimpin oleh seorang pemimpin yang sudah menjabat dalam waktu yang lama, diktator, dan mengekang kebebasan rakyat dalam partisipasi politik. Adapun perbedaannya di Tunisia demonstrasi lebih dipicu tidak dihargainya hak asasi manusia, di Mesir karena perekonomian yang parah dan kecenderungan Mesir pada Barat. Sementara itu Libya karena kekuasaan Muammar Qadhafi yang menekan oposisi pemerintah. Gerakan revolusi menjatuhkan pemimpin-pemimpin diktator dari negara Arab satu ke negara lainnya (the Arab Spring) merupakan efek teori domino. Teori ini menggambarkan saling keterkaitan atau hubungan suatu ideologi dan pengaruhnya, suatu agama, suatu budaya sekuler, kebijakan politik dan moneter, maupun saling berhubungan antara negara-negara dengan mengambil fenomena yang terjadi. Dalam permainan domino, jika tokoh kunci diambil oleh penyusun, maka seluruh bangunan kartu itu akan runtuh secara berurutan.

\section{DAFTAR PUSTAKA}

Abdurrahman, M. "Mesir Bubarkan NDP". Kompas, 18 April 2011, halamam 10.

Agung, D.H. 2011. Khadafi: Anjing Gila dari Sahara. Yogyakarta: Narasi.

Anonim. 2011. "Mubarak dan Dua Putranya Ditahan". Kompas, 14 April 2011, halaman 1.
Anonim. 2011. "Mesir Masih Euforia Kebebasan: Pengadilan di Kairo Diserang karena Tunda Sidang Kasus Polisi”. Kompas, 6 Juli 2011, halaman 8.

Anonim. 2011. "Mesir: Sidang Mubarak Dimulai 3 Agustus". Kompas, 26 Juli 2011, halaman 10.

Anonim. 2011."Mesir: Sidang Dijaga Ketat". Kompas, 3 Agustus 2011), halaman 9.

Anonim. 2012. "Mesir: Vonis di Hari Sabtu". Kompas, 5 Juni 2012, halaman 10.

Bahaudin, A. 2012. Menyingkap Perjalanan Hidup Tokoh-Tokoh Diktator Kejam Dunia. Yogyakarta: Buku Pintar.

Daliman. 2012. Metode Penelitian Sejarah. Yogyakarta: Penerbit Ombak.

Gazalba, S. 1981. Sistematika Filsafat. Jakarta: Bulan Bintang.

Gottschalk, L. 1982. "Understanding History", a.b. Nugroho Notosusanto, Mengerti Sejarah. Jakarta: UI Press. hlm. 35.

Hamid, A.R., dan Madjid, M.S. 2011. Pengantar Ilmu Sejarah. Yogyakarta: Penerbit Ombak.

Hanafi dan Al Jabiri, M.A. 2003. Membunuh Setan Dunia. Yogyakarta: IRCiSoD.

Kuntowijoyo. 2003. Metodologi Sejarah Edisi Kedua. Yogyakarta: Tiara Wacana.

Ricardo, D.A. 2011. Catatan Harian Revolusi Mesir Revolusi Rakyat. Jakarta: Arus Timur.

Sjamsuddin, H. 2012. Metodologi Sejarah. Yogyakarta: Penerbit Ombak.

Tamburaka, A. 2011. Revolusi Timur Tengah: Kejatuhan Para Penguasa Otoriter di Negara-Negara Timur Tengah. Yogyakarta: Narasi. 